\title{
Correction to: An exploration of the relationship between density and building energy performance
}

\author{
Steven Jige Quan ${ }^{1,2} \cdot$ Athanassios Economou $^{3} \cdot$ Thomas Grasl $^{4} \cdot$ Perry Pei-Ju Yang ${ }^{5}$
}

(c) Springer Nature Limited 2020

\section{Correction to: URBAN DESIGN International (2020) 25:92-112 \\ https://doi.org/10.1057/s41289-020-00109-7}

Some of the data in the main article text are not consistent with the data in Tables 2-4 in the article and they have been corrected as follows:

On page 101 of the PDF, in the last paragraph the sentence "it can be as high as $17.7 \%$ " has been corrected to "It can be as high as $10.8 \%$ ". The sentence "the contextual density influence can be -2.1 to $-7.4 \%$ on the base of the individual building scenario without urban context" has been corrected to "the contextual density influence can be -7.3 to $5.5 \%$ on the base of the individual building scenario without urban context".

On page 103 of the PDF, in the second paragraph the sentence "the direct density influence can be as high as $17.6 \%$ " has been corrected to "the direct density influence can be as high as $10.8 \%$ ". The sentence "the contextual density influence ranges from -9.4 to $-0.7 \%$ " has been corrected to "the contextual density influence ranges from -7.3 to $16.6 \%$ ". The following sentences have been deleted: "For each

The original article can be found online at https://doi.org/10.1057/ s41289-020-00109-7.

Perry Pei-Ju Yang

perry.yang@design.gatech.edu

1 City Energy Lab, Graduate School of Environmental Studies, Seoul National University, Seoul 08826, South Korea

2 Environmental Planning Institute, Graduate School of Environmental Studies, Seoul National University, Seoul 08826, South Korea

3 Shape Computation Lab, School of Architecture, Georgia Institute of Technology, Atlanta, GA 30308, USA

4 R\&D, SWAP Architects, Neustiftgasse 32-34/2/8, Vienna 1070, Austria

5 Eco Urban Lab, School of City and Regional Planning and School of Architecture, Georgia Institute of Technology, Atlanta, GA 30308, USA typology, the variation range decreases with the increasing cover ratio. The Courtyard typology seems to have a larger urban context influence than the others, probably because it is more sensitive to microclimate effects due to its larger surface area".

On page 107, in the first paragraph the sentence "when the building cover ratio is $50 \%$, this threshold density is 4.0 (Fig. 14)" has been corrected to "when the building cover ratio is $50 \%$, this threshold density is $3.0-3.5$ (Fig. 14)". The sentence "for the Pavilion typology, the shading + microclimate scenario shows the EUI values $2.1-7.4 \%$ lower than the individual building scenario (Fig. 8)" has been corrected to "for the Pavilion typology, the shading + microclimate scenario shows the EUI values vary by -7.3 to $5.5 \%$ compared to the individual building scenario (Fig. 8)".

Publisher's Note Springer Nature remains neutral with regard to jurisdictional claims in published maps and institutional affiliations. 